\title{
Developing Preliminary Steps in a Pharmacist Communication - Patient Outcome Pathway
}

\author{
Bernadette Chevalier, Bernadette M Watson, Michael A Barras, and William N Cottrell
}

\begin{abstract}
Background: Nonadherence to medication therapy has been associated with poor health outcomes and increased health care costs. The literature describes pharmacists as key health care professionals in identifying and addressing nonadherence issues but does not explain how and why effective pharmacist-patient communication affects patients' medication adherence. Previously published pathways used in linking effective physician-patient communication to patient outcomes are proposed for the context of pharmacist-patient communication.

Objectives: To develop preliminary steps in a pharmacist communication - patient outcome pathway, adapted from a physician-patient communication pathway,

Methods: This longitudinal descriptive study, which took place in a large quaternary hospital, involved hospital pharmacists and patients. Patients' assessment of pharmacist communication behaviours and reporting of patient satisfaction occurred after the pharmacist-patient consultation. Medication-taking behaviour questionnaires were administered before the consultation and again 4 weeks after discharge. Developing the preliminary pathway (based on previously established physician communication pathways) involved 2 steps, with investigation of the following associations: (1) between patient-reported effective communication by pharmacists, as per the Communication Accommodation Theory (CAT), and patient satisfaction; and (2) between patient-reported pharmacist communication and satisfaction and patients' medicationtaking behaviour.
\end{abstract}

Results: Twelve pharmacists and 48 patients participated. For step 1, almost all patient-reported pharmacist communication behaviours were positively correlated with patient satisfaction statements. Strong associations between CAT-related pharmacist communication behaviours and patient satisfaction highlighted the pharmacists' behaviours that are important to patients and necessary for effective conversations to take place. In step 2, there were fewer correlations of medication-taking behaviour indices with pharmacist communication behaviours and patient satisfaction.

Conclusions: This study showed how a preliminary pharmacist communication - patient outcome pathway could be successfully adapted from existing physician communication pathways. Such pathways provide an initial platform upon which future pharmacist communication patient outcome research can be built.

\section{RÉSUMÉ}

Contexte : Le non-respect de la pharmacothérapie a été associé à de mauvais résultats sur la santé et à une augmentation des coûts des soins de santé. La documentation actuelle décrit les pharmaciens comme étant les professionnels de la santé les mieux placés pour déceler les problèmes de non-respect de la prise de médicaments et pour y répondre. Toutefois, elle n'explique pas comment ni pourquoi une communication efficace entre le pharmacien et le patient incite le patient à respecter sa médication. Les parcours qui ont aidé les médecins à améliorer l'efficacité de la communication avec leurs patients sont désormais proposés aux pharmaciens dans le contexte de leur relation avec le patient.

Objectifs : Développer les étapes préliminaires d'un parcours de communication entre le pharmacien et le patient adapté à partir des résultats tirés du parcours de communication entre le médecin et le patient.

Méthodes : Cette étude descriptive longitudinale, qui s'est déroulée dans un important hôpital de soins quaternaires, portait sur les pharmaciens d'hôpitaux et les patients. L'évaluation par les patients des comportements de communication des pharmaciens et le rapport sur la satisfaction du patient se sont déroulés après la consultation qui a eu lieu entre le pharmacien et le patient. Les questionnaires relatifs à la prise de médicaments ont été administrés avant la consultation et à nouveau quatre semaines après le congé hospitalier. Lélaboration du parcours préliminaire (basée sur les parcours de communication du médecin déjà établis) comportait deux étapes servant à examiner les associations suivantes : (1) le rapport qu'ont fait les patients sur l'efficacité de la communication des pharmaciens conformément à la théorie de l'accommodation de la communication (TAC) et la satisfaction du patient et (2) le rapport qu'ont fait les patients sur la communication des pharmaciens ainsi que leur satisfaction et la prise de médicaments des par les patients.

Résultats : Douze pharmaciens et 48 patients ont participé à l'étude. Concernant la première étape, presque tous les patients ont rapporté que les comportements de communication des pharmaciens étaient positivement corrélés aux énoncés de satisfaction des patients. Les fortes associations entre les comportements de communication liés à la TAC du pharmacien et la satisfaction des patients mettaient en exergue les comportements des pharmaciens qui sont importants pour les patients et nécessaires pour accroître l'efficacité des conversations. Concernant la deuxième étape, les corrélations étaient moindres entre les indices de comportement liés à la prise de médicaments et les comportements de communication du pharmacien ainsi que la satisfaction du patient. 
Keywords: communication-outcome pathway, hospital pharmacist communication, patient satisfaction, medication adherence, Communication Accommodation Theory (CAT)

Can J Hosp Pharm. 2019;72(4):271-81
Conclusions : Cette étude a démontré comment un parcours de communication préliminaire entre le pharmacien et le patient peut être adapté avec succès à partir des résultats tirés des parcours de communication existants destinés au médecin. De tels parcours fournissent une plateforme initiale sur laquelle peuvent se développer les recherches futures servant à démontrer les résultats sur les patients de la communication du pharmacien.

Mots-clés : voie communication-résultat, communication des pharmaciens d'hôpitaux, satisfaction des patients, respect de la médication, théorie de l'accommodation de la communication (TAC)

\section{INTRODUCTION}

Tonadherence to medications results in poor health outcomes 1 for patients and increased costs to health care systems. ${ }^{1,2}$ Patients' nonadherence to medications varies considerably depending on the condition being treated. For example, nonadherence rates range from $35 \%$ to $69 \%$ for patients with type 2 diabetes mellitus, from $40 \%$ to $70 \%$ for those with asthma, and from $25 \%$ to $65 \%$ for those with hypertension. ${ }^{3-5}$ The multiple determinants of nonadherence include socioeconomic factors, factors related to the health care team or the health system, condition-related factors, treatment-related factors, and patientrelated factors. ${ }^{4}$ Determinants attributed to health care providers, such as good relationships and effective communication with patients, have been found to facilitate medication adherence for the management of pain, diabetes, epilepsy, HIV/AIDS, tuberculosis, and hypertension, and for tobacco cessation. ${ }^{4}$

Pharmacists have been identified as key health care professionals in identifying and addressing nonadherence issues. ${ }^{6,7}$ While much has been published about the pharmacist's role in improving medication adherence, ${ }^{4,8-11}$ there is scant information about how and why effective pharmacist-patient communication might affect patients' medication adherence. This is a substantial gap in understanding the role that pharmacists play in patients' adherence to their medications, particularly over time and once a patient leaves the inpatient setting.

Conversely, numerous empirical studies have investigated the effect of good physician-patient relationships and effective communication on clinical outcomes, with such studies showing a positive relationship between effective physician communication skills and patients' adherence to treatment. ${ }^{12-15}$ For example, a meta-analysis of 106 studies correlated physician-patient communication with patient adherence and also considered 21 experimental intervention studies evaluating the effect of physician communication training on patient adherence. ${ }^{13}$ The researchers reported that the odds of a patient being adherent to treatment were 2.16 times better if the physician communicated well and 1.62 times better if the physician had received communication training, relative to those patients whose physicians had not had communication skills training. ${ }^{13}$
However, there are inconsistent findings within the medical literature, whereby attributes of effective physician communication have not always been associated with treatment adherence and other patient outcomes. ${ }^{16}$ Research in this area has been criticized as not being clear about which aspects of physicianpatient communication contribute to which health outcomes. ${ }^{17}$ Furthermore, research into communication between health care providers and patients has failed to suggest pathways and processes to explain how effective communication could be associated with positive patient outcomes. Street and others ${ }^{17}$ posited that the links between the effectiveness of physician-patient communication and patient outcomes are often complex. Although positive communication exchanges may directly result in desirable health outcomes for patients, these interactions often follow indirect paths leading first to proximal outcomes (e.g., rapport-building, patient satisfaction) and then to intermediate outcomes (e.g., self-care skills, treatment adherence), before achieving health outcomes (e.g., cure, emotional well-being) (Figure 1). ${ }^{17}$

Pharmacist communication - patient outcome research is relatively new and consequently understudied in comparison to the work completed by physician-patient communication researchers. Given the complexity of communication - health outcome research, it is important to use the lessons learned from physician communication studies and to develop "pharmacist communication to patient outcome" processes that allow the clear delineation of which measured communication behaviours are linked to which patient outcomes.

This research study intends to demonstrate how such a preliminary pathway could be adapted from the physician communication processes described by Street and others. ${ }^{17}$ Relationships are explored, in multiple steps, among effective pharmacist-patient exchanges, patient satisfaction, and patients' medication-taking behaviour. To begin, relational aspects between communication and medication adherence are studied through a pathway adapted from previous research ${ }^{17}$ (as depicted in Figure 1) to fit the pharmacist-patient context. Relationships between proximal outcomes, such as effectively used communication strategies and patient satisfaction, are studied. Then possible associations between these proximal outcomes and the intermediate outcome of adherence to treatment are explored (Figure 2). 


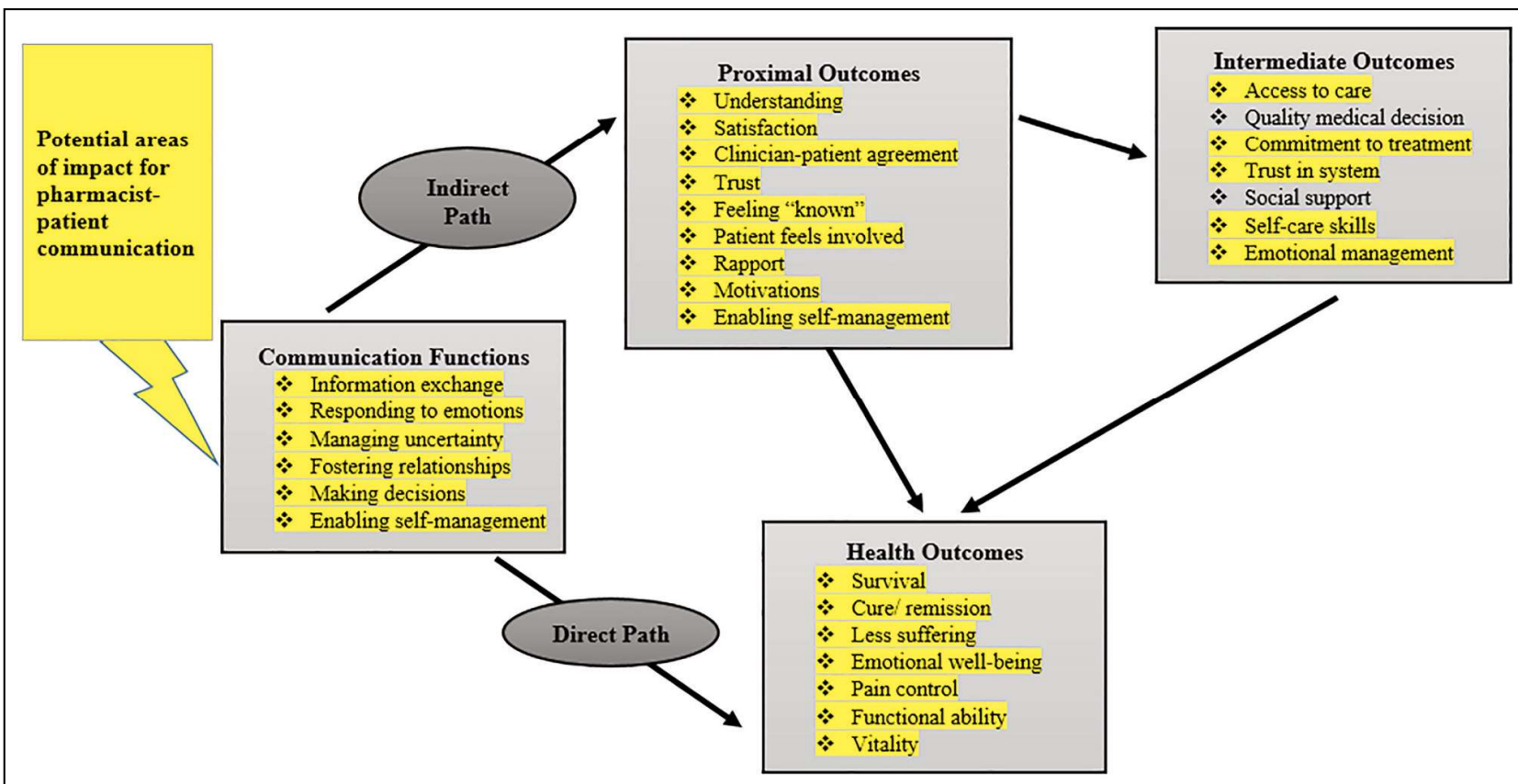

Figure 1. Pathways from pharmacist-patient communication to health outcomes. Potential areas for pharmacistpatient communication are shown in yellow. Adapted from Patient Education and Counseling, volume 75, no. 3, Street RL Jr, Makoul G, Arora NK, Epstein RM. "How does communication heal? Pathways linking clinician-patient communication to health outcomes", pages 295-301, (c) 2009, with permission from Elsevier.

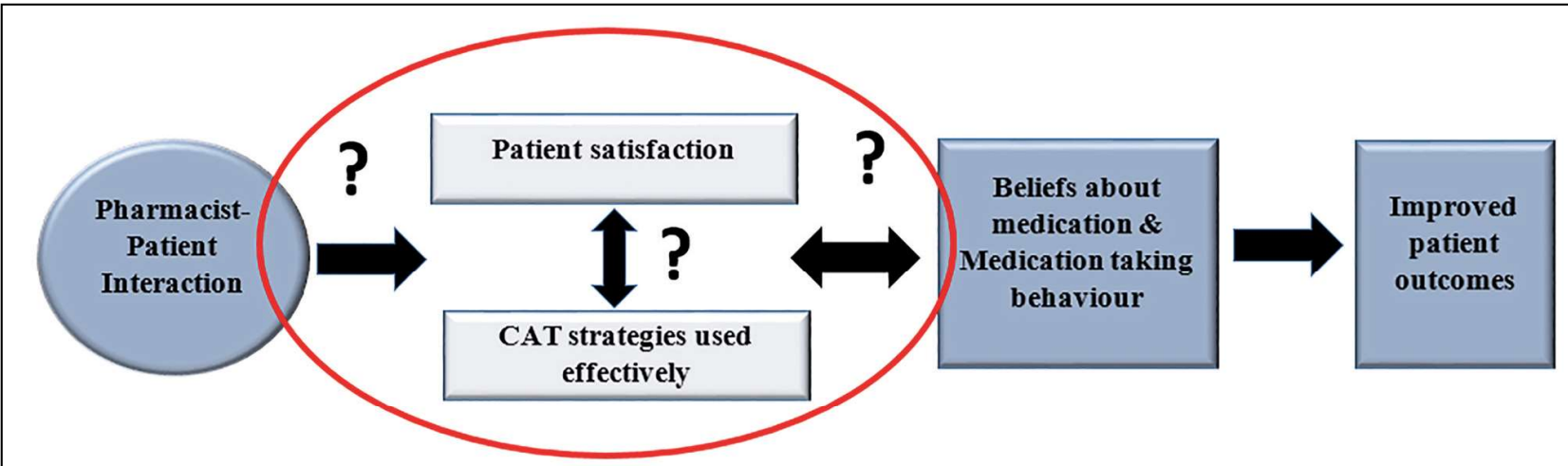

Figure 2. Relationships among effective communication, patient satisfaction, and medication-taking behaviour. CAT = Communication Accommodation Theory.

This study invoked the Communication Accommodation Theory (CAT) as the theoretical framework for all aspects of the research (i.e., design, data collection, analysis, and presentation of results and discussion). CAT is a widely used framework in health communication research ${ }^{18-22}$ to help explain the emotional, behavioural, and motivational processes underlying communication exchanges. ${ }^{23}$ The "CAT strategies used effectively" (as shown within Figure 2) are 5 strategies that are measured to establish the presence or lack of effective communication in interactions between patients and health professionals. ${ }^{24-26}$ These strategies are approximation (matching another speaker's speech rate, volume, accent/dialect), ${ }^{27}$ interpretability (using easily understood language and terms), ${ }^{24}$ emotional expression (appropriately responding to the other speaker's emotional needs), ${ }^{26}$ discourse management (engaging and maintaining conversations), ${ }^{28}$ and interpersonal control (empowering/promoting equality between speakers). $25,29,30$ CAT describes communication as being either accommodative (i.e., adjustments are made to bring speakers closer linguistically) 
or non-accommodative (i.e., involving behaviour that creates barriers or linguistic distance between speakers). ${ }^{24}$ In the pharmacist-patient communication context, accommodation takes place when pharmacists slow down their speech to match that of the patients, use medical terms understood by patients, and ask open-ended questions to enage patients in conversations about their medications. Conversely, non-accommodation occurs when pharmacists do not meet patients' conversational needs. For example, this might happen when pharmacists relay information in a one-way direction or frequently interupt patients, not allowing them to ask questions about their medications.

This research was intended to be exploratory. Data were collected as part of earlier research that focused on a qualitative investigation of communication effectiveness between hospital pharmacists and patients during medication counselling. ${ }^{31}$ Therefore, this study was not designed or powered to detect differences in medication-taking behaviours over time. Rather, with this novel study, we sought to lay the foundation for the development of preliminary pharmacist communication - patient outcome pathways that could direct future research. Importantly, this study was longitudinal, with patients being followed over a 1-month period after discharge from hospital.

The study objective was to develop preliminary steps in a pharmacist communication - patient outcome pathway by adapting a physician communication pathway to the pharmacistpatient communication context. To achieve this objective, we undertook steps to show

- how effective pharmacist communication (using CAT) and patient satisfaction are associated (step 1)

- how patients' medication-taking behaviour is associated with patient-reported effective communication and satisfaction (step 2)

\section{METHODS}

\section{Ethics Approval}

Research ethics approval was received from the Royal Brisbane and Women's Hospital Human Research Ethics Committee (HREC/15/QRBW/433) and from the School of Pharmacy, The University of Queensland Ethics Committee (2015/13). All participants provided written informed consent.

\section{Study Design}

This descriptive study used quantitative methods to address the study's objective, involving 2 steps: (1) measuring the relationship between CAT-related pharmacist communication behaviours and patient satisfaction statements determined through semistructured interviews; (2) correlating pharmacist communication behaviours and patient satisfaction with the results of questionnaires on medication-taking behaviour. Step 2 also included investigating changes in patients' beliefs about their medications and their medication adherence over time.

\section{Recruitment and Data Collection}

Data were collected between November 2015 and April 2016 in a 1000-bed teaching hospital as part of doctoral research that focused on a qualitative investigation of communication effectiveness between hospital pharmacists and patients during medication counselling. Details about the methods used and results reporting communication effectiveness have been published elsewhere. ${ }^{31}$ The current study focused on the data related to patients' assessment of pharmacist communication, patients' satisfaction, and patients' medication-taking behaviour. Two medication-taking behaviour questionnaires, the Beliefs about Medicines Questionnaire (BMQ) ${ }^{32}$ and the 8-point Morisky Medication Adherence Scale (MMAS-8), ${ }^{33,34}$ were administered to patients who consented to participate. Then, each patient underwent a medication consultation with a pharmacist (with audio-recording), which was immediately followed by semistructured interviews held separately with the pharmacist and the patient, to gain each participant's perspective. During these interviews, participants were asked to indicate their opinions about the consultation in terms of their level of agreement (on a 7-point Likert scale) with a series of statements, based on CAT strategies, with one of the statements being worded in reverse. The principal investigator (B.C.) conducted the interviews and answered any questions that participants had about any of the statements.

Four weeks after each patient left the hospital, the BMQ and MMAS-8 were administered again by telephone. This time frame was chosen to allow patients sufficient time to settle in at home and connect with their family physicians and community pharmacists after the initial pharmacist-patient interaction, without being so excessive that patients found it difficult to recall their experience.

\section{Development of Semistructured Interview Guide}

The interview guide consisted of 10 statements based on CAT strategies, reflecting aspects of pharmacist-patient communication, and 3 statements about participants' overall satisfaction. The face and content validity of the statements was assessed by the 3 pharmacists on the research team (B.C., M.A.B., W.N.C.), while the relevance of the statements to the CAT strategies was verified by the psychologist (B.M.W.) on the team. Cronbach $\alpha$ reliability testing was conducted to provide assurance of internal consistency within the 10 CAT-based statements. ${ }^{35}$ The Cronbach $\alpha$ value calculated for the unidimensional scale for the 10 CAT-based statements was 0.75 for patients, above the acceptable 0.7 value. ${ }^{35}$ A Cronbach $\alpha$ of 0.68 was calculated for the 3 patient satisfaction statements. This lower value was not surprising, given that only 3 items were included in the scale. ${ }^{36}$ However, the mean inter-item correlation, which also analyzes internal consistency, was calculated as 0.4 for these patient satisfaction statements and was within the acceptable range $(0.2-0.4) .{ }^{36}$ 
Medication-Taking Behaviour Questionnaires

The BMQ is a validated instrument that assesses patients' beliefs about the necessity of prescribed medications and their concerns about the potential dangers or disruptive effects of their medications. ${ }^{32}$ Patients with strong beliefs about the value of their medications and few concerns about their medicines are more likely to be adherent to their medications. ${ }^{32}$

The MMAS- 8 medication adherence tool, which is composed of 8 questions, requires patients to reflect on their medication-taking behaviours. A score of 8 indicates high adherence, scores of 6 to $<8$ reflect moderate adherence, and scores less than 6 are considered to represent low adherence. ${ }^{33,34}$ The MMAS-8 was chosen because it is a convenient, easy-to-use, validated research tool that has been applied worldwide in a variety of health conditions. ${ }^{34,37-41}$

\section{Data Analysis}

The responses to the BMQ, the MMAS-8 tool, and the semistructured interview statements were recorded in a Microsoft Excel database (Microsoft Corporation, Redmond, Washington). All data were analyzed using SPSS Statistics for Windows, version 25.0 (IBM Corporation, Armonk, New York). A $p$ value of less than 0.05 was considered statistically significant. Because the data were not normally distributed, nonparametric tests were used to analyze the data.

The Spearman correlation was used to test both the relationship between CAT behavioural statements and patient satisfaction statements, and the associations of the CAT and patient satisfaction statements with the 4-week BMQ and MMAS-8 results. For this part of the study, the 4-week postdischarge scores were used, rather than the baseline scores, because this assessment occurred after the pharmacist-patient conversation and would better reflect any effects of the exchange.

BMQ and MMAS- 8 scores for questionnaires administered to patients before the pharmacist-patient conversation were compared with the 4-week postdischarge scores using the Wilcoxon signed-rank test to detect changes in scores over time. The effect size $(r)$ for any significant difference was calculated by dividing the test statistic $(Z)$ by the square root of the number of observations. ${ }^{36}$ Based on the criteria provided by Cohen, ${ }^{42} r=0.1$ indicates a small effect size, $r=0.3$ indicates a medium effect size, and $r=0.5$ indicates a large effect size.

\section{RESULTS}

Twelve pharmacists engaged 4 separate patients each for a total of 48 medication counselling interactions; however, not all 48 patients who consented to be in the study completed all parts of the study (Figure 3). The majority (10 [83\%]) of the pharmacists who took part in the study were women, with about half being under 30 years of age and having less than 10 years' experience as a pharmacist. Participating patients were mostly men
(27 [56\%]) and over 60 years of age. Patients from both inpatient areas (cardiology, emergency, geriatrics, general medicine, nephrology, neurology, oncology, surgery) and outpatient clinics (heart failure, infectious diseases, renal disease) were included.

\section{Step 1: Relationship between Patients' Assessment of Pharmacists' Communication Behaviours and Patients' Satisfaction}

Overall, high proportions of patients $(>80 \%)$ indicated agreement or strong agreement that pharmacists demonstrated the communication behaviour described in each of the 10 statements. Patients' level of agreement on the 10 statements assessing pharmacists' communication behaviours and their association with the 3 patient satisfaction statements are displayed in Table 1.

\section{Step 2: Relationship of Patients' Assessment of Pharmacists' Communication Behaviours and Level of Satisfaction with Medication-Taking Behaviour Indices}

Almost all correlations with statistical significance involved the BMQ postdischarge necessity score, for which 5 of the pharmacists' communication behaviours and 2 of the patient satisfaction statements were positively correlated (Table 2).

\section{Changes in BMQ and MMAS-8 Scores over Time}

Differences between patients' BMQ and MMAS-8 scores measured before their respective conversations with a pharmacist about their medications and again 4 weeks after the patients had left the hospital are shown in Table 3. No statistically significant differences for any of the BMQ indices were found. Differences in MMAS-8 scores between the 2 time points were significant (median 6.75 versus $7.00 ; p=0.022$ ), although the calculated effect size was small $(r=0.248)$.

The distribution of MMAS-8 scores for the first and second questionnaires is shown in Table 4. Most patients had moderate or high adherence scores for both the first questionnaire (27/45 $[60 \%])$ and the second questionnaire (39/46 [85\%]).

\section{DISCUSSION}

This novel longitudinal, exploratory study has shown how the theoretical communication - patient outcome pathways developed for physicians could be adapted to the pharmacistpatient communication context. This study focused on 2 preliminary steps within the original pathway (Figure 1) to demonstrate how effective communication (using CAT) and patient satisfaction are associated (step 1) and how patients' medication-taking behaviour is associated with patient-reported effective communication and satisfaction (step 2). The most impressive results were the high number of positive correlations between patient-reported 
This single copy is for your personal, non-commercial use only.

For permission to reprint multiple copies or to order presentation-ready copies for distribution, contact CHP at publications@cshp.pharmacy

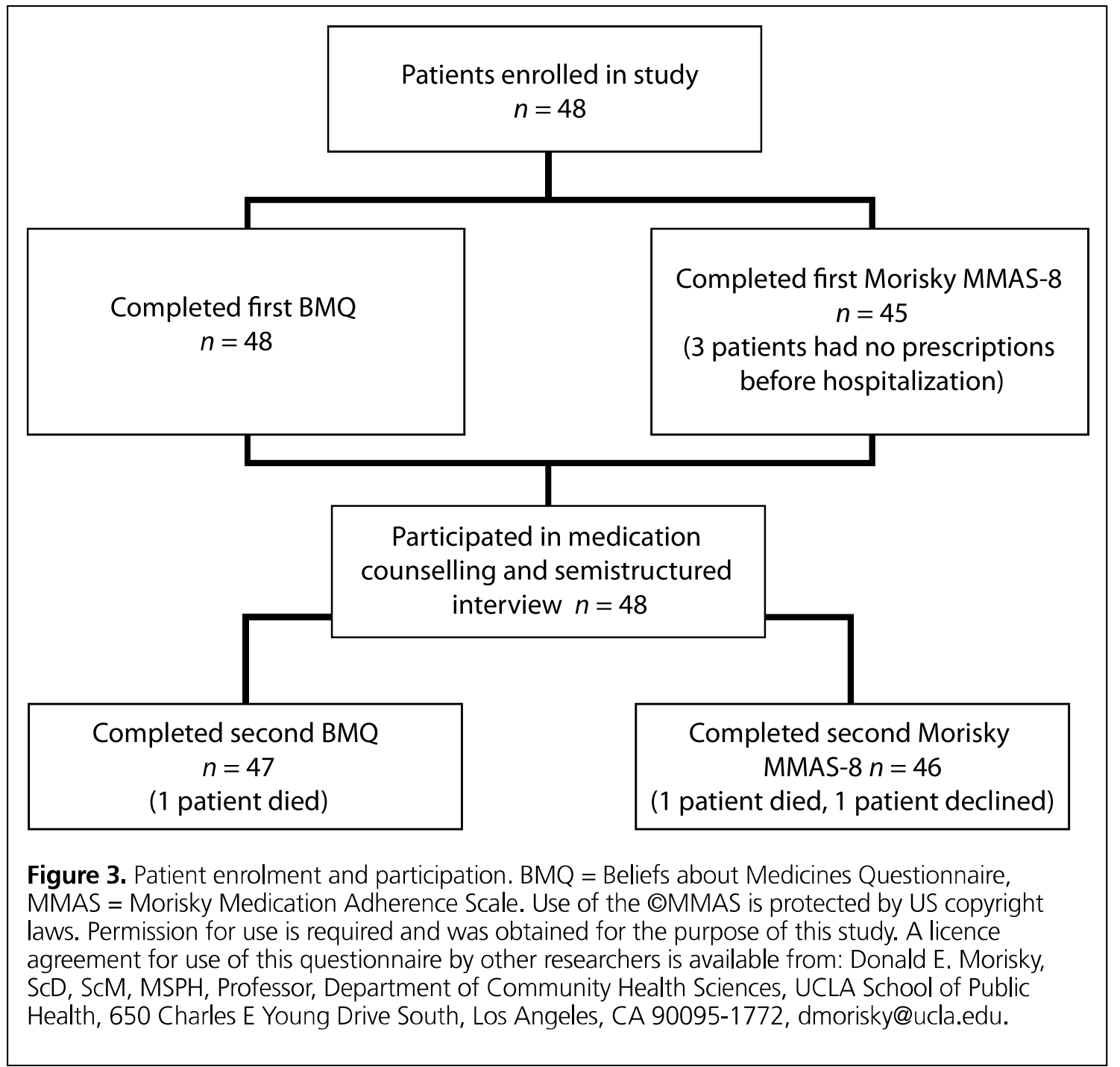

pharmacist communication behaviours and patients' level of satisfaction. These results highlight the pharmacist communication behaviours that are of particular importance to patients and therefore necessary for effective conversations. In addition, some promising trends were observed in terms of correlations between medication-taking behaviours and pharmacist communication behaviours/patient satisfaction. The most important strength of this study is that it has mapped pathways for conducting future research that link pharmacist-patient communication to patient outcomes. This is an important step to facilitate rigorous pharmacist communication research that indicates how and where associations between communication and patient outcomes occur, and to avoid the pitfalls encountered by earlier physician communication researchers, who did not clearly delineate these relationships. ${ }^{17}$

This process of adapting a physician communication pathway for pharmacist communication research revealed some important and interesting findings. Step 1 of this investigation mirrored the relationships between "communication functions" and "proximal outcomes", as well as the interplay of communication behaviours and patient satisfaction found within "proximal outcomes" of Figure $1 .{ }^{17}$ The first step showed that nearly all patient-assessed pharmacist communication behaviours were positively correlated with all 3 patient satisfaction statements. This finding implied that the more patients experienced these pharmacist communication behaviours, the higher their reported levels of satisfaction with the pharmacist-patient exchanges. However, 2 exceptions were noted for the communication behaviour statements. Statement 2 of Table 1, "The pharmacist used medical terms I could understand", was the only statement that was reverse-worded in the semistructured interview for patients. It is possible that the use of reverse wording may have been confusing to some patients, resulting in incorrect interpretation and scoring of the pharmacist's behaviour. Only one patient 
This single copy is for your personal, non-commercial use only.

For permission to reprint multiple copies or to order presentation-ready copies for distribution, contact CJHP at publications@cshp.pharmacy

Table 1. Relationship between Patients' Assessment of Pharmacists' Communication Behaviours and Patients' Satisfaction

\begin{tabular}{|c|c|c|c|c|c|}
\hline \multirow[b]{2}{*}{$\begin{array}{l}\text { Pharmacist Communication } \\
\text { Behaviour Statement }\end{array}$} & \multirow[b]{2}{*}{$\begin{array}{l}\text { Associated CAT } \\
\text { Strategy }\end{array}$} & \multirow[b]{2}{*}{$\begin{array}{l}\% \text { of Patients } \\
\text { Agreeing with } \\
\text { Pharmacist } \\
\text { Behaviour } \\
(n=48)^{*}\end{array}$} & \multicolumn{3}{|c|}{$\begin{array}{c}\text { Patient Satisfaction Statement; } \\
\text { Spearman Rank Correlation with Statement }\end{array}$} \\
\hline & & & $\begin{array}{l}\text { The pharmacist } \\
\text { did a good job } \\
\text { helping me } \\
\text { understand my } \\
\text { medicines }\end{array}$ & $\begin{array}{l}\text { I was satisfied } \\
\text { with my } \\
\text { experience I had } \\
\text { with the } \\
\text { pharmacist }\end{array}$ & $\begin{array}{l}\text { This was an } \\
\text { effective } \\
\text { conversation with } \\
\text { the pharmacist } \\
\text { (I got what } \\
\text { I needed) }\end{array}$ \\
\hline $\begin{array}{l}\text { The pharmacist spoke clearly, } \\
\text { so I could understand what they } \\
\text { were saying. }\end{array}$ & Approximation & 100 & $0.361 \dagger$ & $0.371 \neq$ & $0.388 \neq$ \\
\hline $\begin{array}{l}\text { 2. The pharmacist used medical terms } \\
\text { I could understand. }\end{array}$ & Interpretability & 88 & -0.131 & 0.049 & -0.031 \\
\hline $\begin{array}{l}\text { 3. The pharmacist explained how my } \\
\text { medication works in a way I could } \\
\text { easily understand. }\end{array}$ & Interpretability & 100 & $0.369 \dagger$ & $0.333 \dagger$ & $0.601 \neq$ \\
\hline $\begin{array}{l}\text { 4. The pharmacist gave me enough } \\
\text { time to think about the medication } \\
\text { information given to me so that } \\
\text { I could ask any questions I had. }\end{array}$ & $\begin{array}{l}\text { Discourse } \\
\text { management }\end{array}$ & 96 & 0.196 & $0.306+$ & $0.498 \ddagger$ \\
\hline $\begin{array}{l}\text { 5. The pharmacist paid attention and } \\
\text { listened to my concerns about my } \\
\text { medications. }\end{array}$ & $\begin{array}{l}\text { Discourse } \\
\text { management }\end{array}$ & 100 & $0.501 \ddagger$ & $0.328 \dagger$ & $0.431 \neq$ \\
\hline $\begin{array}{l}\text { 6. The pharmacist allowed me to } \\
\text { interrupt to ask questions. }\end{array}$ & $\begin{array}{l}\text { Interpersonal } \\
\text { control }\end{array}$ & 98 & $0.357 \dagger$ & $0.334 \dagger$ & $0.457 \neq$ \\
\hline $\begin{array}{l}\text { 7. I felt like the pharmacist thought } \\
\text { my worries and questions about } \\
\text { my medicines were important. }\end{array}$ & $\begin{array}{l}\text { Emotional } \\
\text { expression }\end{array}$ & 98 & $0.597 \ddagger$ & $0.443 \ddagger$ & $0.383 \ddagger$ \\
\hline $\begin{array}{l}\text { 8. The pharmacist spoke to me in } \\
\text { a respectful and courteous manner. }\end{array}$ & $\begin{array}{l}\text { Emotional } \\
\text { expression }\end{array}$ & 100 & $0.432 \ddagger$ & $0.592 \ddagger$ & $0.395 \ddagger$ \\
\hline $\begin{array}{l}\text { 9. The pharmacist encouraged me to } \\
\text { talk to my doctor and/or } \\
\text { community pharmacist about } \\
\text { different medication options } \\
\text { available to me. }\end{array}$ & $\begin{array}{l}\text { Interpersonal } \\
\text { control }\end{array}$ & 87 & $0.383 \dagger$ & $0.389 \neq$ & $0.318+$ \\
\hline $\begin{array}{l}\text { 10. The pharmacist encouraged me } \\
\text { to take responsibility for managing } \\
\text { my health. }\end{array}$ & $\begin{array}{l}\text { Interpersonal } \\
\text { control }\end{array}$ & 87 & 0.143 & 0.117 & $0.303+$ \\
\hline
\end{tabular}

satisfaction statement, "This was an effective conversation with the pharmacist", was positively correlated with statement 10 , which described the pharmacist as encouraging the patient to take responsibility for managing his or her own health. It is unclear why a positive correlation was not observed between this pharmacist behaviour statement and the 2 other patient satisfaction statements. However, patients' assignment of lower scores to pharmacists' communication behaviour statements did not necessarily mean that pharmacists were non-accommodative to patients' conversational needs. Instead, it sometimes meant that the pharmacists' behaviour was not observed by the patients in their particular interactions.

Several pharmacist communication behaviours were strongly correlated with patient satisfaction statements. Of note, pharmacist behaviour statements 1 and 3 to 9 (Table 1) were strongly correlated with all 3 patient satisfaction statements. Other researchers have found positive associations between similar communication behaviours and patient satisfaction. For example, in a study by White, ${ }^{43} \mathrm{UK}$ pharmacists who were trained in a cognitive behavioural therapy framework provided medication consults to patients on an inpatient mental health ward. Patients expressed high levels of satisfaction with having their questions answered in a way they could understand and being treated with respect and dignity. ${ }^{43}$ Patients surveyed at a US immunization clinic after receipt of counselling and vaccination by a pharmacist expressed satisfaction in having the "pharmacist explain things to me in a way that I can understand" and having the "pharmacist [spend] as much time as is needed with me". ${ }^{44}$ Australian researchers eliciting patients' assessment of their experience and level of satisfaction with prescribing pharmacists in a surgical preadmission clinic reported relationships between a number of assessment statements and patient satisfaction similar to those 
This single copy is for your personal, non-commercial use only.

For permission to reprint multiple copies or to order presentation-ready copies for distribution, contact CJHP at publications@cshp.pharmacy

Table 2. Relationship of Patients' Assessment of Pharmacists' Communication Behaviours and Satisfaction with BMQ and MMAS-8 Scores

\section{Statement}

Pharmacist communication behaviour

1. The pharmacist spoke clearly, so I could understand what they were saying.

2. The pharmacist used medical terms I could understand.

3. The pharmacist explained how my medication works in a way I could easily understand

4. The pharmacist gave me enough time to think about the medication information given to me so that I could ask any questions I had.

5. The pharmacist paid attention and listened to my concerns about my medications.

6. The pharmacist allowed me to interrupt to ask questions.

7. I felt like the pharmacist thought my worries and questions about my medicines were important.

8. The pharmacist spoke to me in a respectful and courteous manner.

9. The pharmacist encouraged me to talk to my doctor and/or community pharmacist about different medication options available to me.

10. The pharmacist encouraged me to take responsibility for managing my health.

\section{Patient satisfaction statement}

11. The pharmacist did a good job helping me understand my medicines.

12. I was satisfied with my experience I had with the pharmacist.

13. This was an effective conversation with the pharmacist.

\section{$\%$ of Patients Agreeing with Statement $(n=48)$}

Score; Spearman Rank Correlation

Pe

Postdischarge
Necessity Score
(BMQ)
$(n=47)$

Postdischarge
Concern Score
(BMQ)
$(n=47)$

0.272

0.226

$0.332 \dagger$

$0.427 \ddagger$

0.251

0.143

$0.296 \dagger$

$0.328 \dagger$

$0.388 \ddagger$

0.271

$0.326 \dagger$

$0.381 \neq$

0.167
0.008

$-0.360+$

$-0.028$

$-0.042$

0.010

$-0.052$

0.087

$-0.055$

0.117

$-0.53$

$-0.036$

Postdischarge

MMAS-8

Score

$(n=46)$

$-0.071$

0.042

$-0.185$

$-0.062$

$-0.065$

$-0.103$

$-0.116$

$-0.082$

$-0.225$ copyright laws. Permission for use is required and was obtained for the purpose of this study. A licence agreement for use of this questionnaire by other researchers is available from: Donald E Morisky, SCD, SCM, MSPH, Professor, Department of Community Health Sciences, UCLA School of Public Health, 650 Charles E Young Drive South, Los Angeles, CA 90095-1772, dmorisky@ucla.edu.

* "Agreement" consists of the sum of "agree" plus "strongly agree" responses or, in the case of reverse-worded statements, "disagree" plus "strongly disagree" responses.

tCorrelation significant at the $p<0.05$ level (2-tailed).

¥Correlation significant at the $p<0.01$ level (2-tailed).

\section{Table 3. BMQ and MMAS-8 Scores at 2 Points in Time}

\begin{tabular}{lccc} 
& \multicolumn{2}{c}{ Timing of Questionnaire*; Median Scoret (Range) } & \\
\cline { 2 - 3 } Test & First Questionnaire & Second Questionnaire & Wilcoxon Signed-Rank Test \\
\hline BMQ & $n=48$ & $n=47$ & \\
Necessity domain & $21(11-25)$ & $21(12-25)$ & $Z=0, p>0.99$ \\
Concern domain & $12(5-22)$ & $13(5-22)$ & $Z=1.690, p=0.091$ \\
\hline MMAS-8 & $n=45$ & $n=46$ & $Z=2.298, p=0.022 ;$ \\
& $6.75(0.5-8)$ & $7.00(1-8)$ & $r=0.248$ \\
\hline
\end{tabular}

BMQ = Beliefs about Medicines Questionnaire, MMAS-8 = 8-point Morisky Medication Adherence Scale. Use of the CMMAS is protected by US copyright laws. Permission for use is required and was obtained for the purpose of this study. A licence agreement for use of this questionnaire by other researchers is available from: Donald E Morisky, ScD, ScM, MSPH, Professor, Department of Community Health Sciences, UCLA School of Public Health, 650 Charles E Young Drive South, Los Angeles, CA 90095-1772, dmorisky@ucla.edu

* First questionnaire was administered before patient's conversation with pharmacist, and second questionnaire took place 4 weeks after patient left hospital.

†Possible BMQ scores range from 5 to 25 for each of 2 domains (necessity and concern); higher scores indicate a stronger belief in that domain. MMAS-8 scores range from 0 to 8; score $<6$ indicates low adherence, score from 6 to $<8$ indicates moderate adherence, and score of 8 indicates high adherence. 
Table 4. Distribution of MMAS-8 Scores at 2 Points in Time

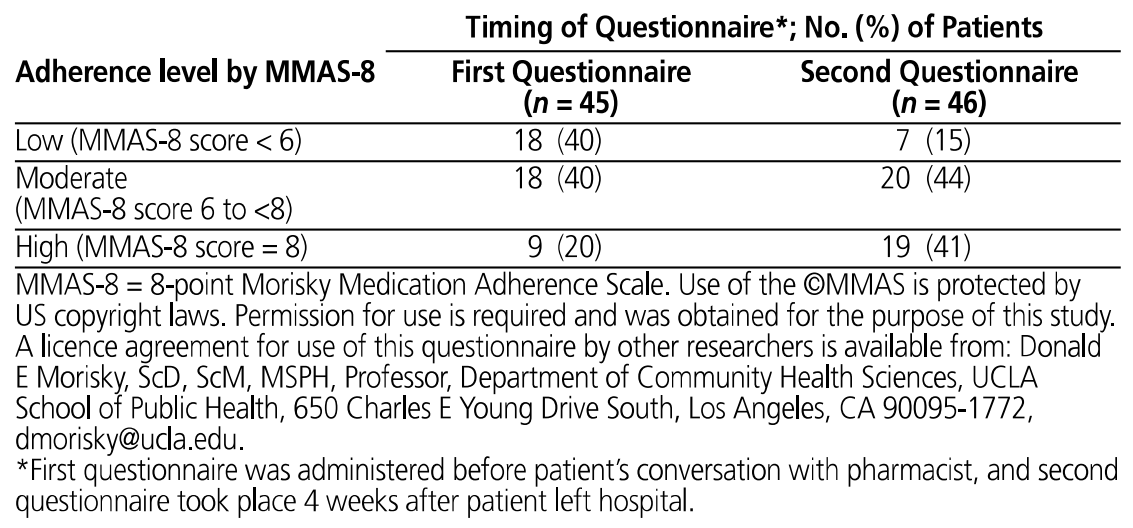

observed in the current study. These assessments included "explained clearly", "provided relevant information", "listened", "answered questions in a way easily understood", and "understood medication concerns expressed". ${ }^{4}$

Step 2 of this study explored the link between "proximal" and "intermediate" outcomes (as shown in Figure 1) by investigating whether a relationship between pharmacists' communication behaviour or patients' level of satisfaction exists with patients' medication-taking behaviours. ${ }^{17}$ The positive and statistically significant correlations between pharmacist communication behaviours and patients' satisfaction occurred mainly with the BMQ postdischarge necessity score. This positive correlation is understandable, because patients who have experienced a pharmacist-patient interaction in which the pharmacist provided well-explained information, at a pace that allowed patients enough time to ask questions, and addressed medication issues would likely appreciate the need for their medication and its benefits to their health and well-being. Patients who felt that the pharmacist was empathetic and provided reassurance in response to their concerns about their medications may have stronger beliefs that their medications are beneficial. Therefore, the strong positive correlations between 2 of the overall satisfaction statements ("I was satisfied with my experience I had with the pharmacist" and "The pharmacist did a good job helping me understand my medicines") and the necessity score were not surprising. However, it is unknown why the same associations were not observed for the satisfaction statement "This was an effective conversation with the pharmacist."

There was only one negative statistically significant correlation, which occurred between statement 2 ("The pharmacist used medical terms I could understand") and the postdischarge concern score. This indicates that the more patients experienced pharmacists using laypersons' terms rather than medical terminology, the less patients expressed concerns about the harmful effects of their medications.

No statistically significant associations were observed for any pharmacist behaviour statements, patient satisfaction, and postdischarge medication adherence (MMAS-8) scores. In addition, a significant difference in medication adherence indices measured at 2 time points was observed only for the MMAS- 8 scores. For all other medication adherence indices, differences between the first and second time points were small. In this study population, many patients had been identified as moderately and highly adherent; therefore, there was little or no room for a change in adherence scores to occur. Other researchers have reported that initial scores reflecting higher levels of medication adherence make it difficult to see any significant changes in medication-taking behaviour. $^{34,46}$

This study had potential limitations. Patients may have provided socially desirable responses when they assessed pharmacists' communication behaviours and indicated their levels of satisfaction. Although patient interviews were held immediately after their conversations with the pharmacist, it is possible that the patients did not recall specific details about these interactions. These biases may have also occurred at the 4-week follow-up. This research was conducted at a single public hospital, and therefore the results may not be transferable to all specialty areas at other hospitals or to rural or private hospitals. Patient outcomes such as medication adherence are influenced by multiple factors in addition to effective health professional - patient relationships and communication. ${ }^{4}$ Therefore, the pharmacist communication - patient outcome pathway explored in this study helps to explain how different aspects of communication may be associated with a patient outcome such as medication adherence, but the links do not imply causality. Although the medication-taking behaviour questionnaires used in this study have been validated in a range of medical conditions and cultural contexts, ${ }^{34,37-41}$ using additional measures of medication adherence, such as prescription fills, could have strengthened the methodology of this study. Future research will address these issues.

\section{CONCLUSION}

In this study, a physician communication - patient outcome pathway was adapted to the pharmacist-patient communication 
This single copy is for your personal, non-commercial use only.

For permission to reprint multiple copies or to order presentation-ready copies for distribution, contact CJHP at publications@cshp.pharmacy

context. This research has introduced a valuable foundation for future work by providing some preliminary process mapping of how effects of the pharmacist-patient communication exchange are linked to proximal and intermediate clinical outcomes. ${ }^{17}$ For example, next steps in this research might include a randomized controlled trial with sufficient baseline numbers of patients with low adherence, subjected to multiple communication interventions and followed over time, to allow firm conclusions to be drawn.

By adapting an outcome pathway from the literature, a framework has been created for conducting exploratory research to investigate the relationship between effective pharmacistpatient exchanges and patients' medication-taking behaviour. This research represents an important preliminary step in establishing links between pharmacist-patient communication and patient outcomes.

\section{References}

1. Simpson SH, Eurich DT, Majumdar SR, Padwal RS, Tsuyuki RT, Varney J, et al. A meta-analysis of the association between adherence to drug therapy and mortality. BMJ. 2006;333:15.

2. Sokol MC, Mcguigan KA, Verbrugge RR, Epstein RS. Impact of medication adherence on hospitalization risk and healthcare cost. Med Care. 2005; 43(6):521-30.

3. Nielsen JØ, Shrestha AD, Neupane D, Kallestrup P. Non-adherence to anti-hypertensive medication in low- and middle-income countries: a systematic review and meta-analysis of 92443 subjects. J Hum Hypertens. 2016;31(1):14-21.

4. Adherence to long-term therapies - evidence for action. Geneva $(\mathrm{CH})$ : World Health Organization; 2003 [cited 2018 Jun 3]. Available from: http://www.who.int/chp/knowledge/publications/adherence_report/en/

5. Zomahoun HTV, De Bruin M, Guillaumie L, Moisan J, Grégoire JP, Pérez $\mathrm{N}$, et al. Effectiveness and content analysis of interventions to enhance oral antidiabetic drug adherence in adults with type 2 diabetes: systematic review and meta-analysis. Value Health. 2015;18(4):530-40.

6. Braithwaite S, Shirkhorshidian I, Jones K, Johnsrud M. The role of medication adherence in the U.S. healthcare system. Washington (DC): Avalare Health LLC; 2013 [cited 2018 Jun 3]. Available from: http://citeseerx.ist.psu.edu/ viewdoc/download?doi=10.1.1.357.6179\&rep=rep1 \&type=pdf

7. Nieuwlaat R, Wilczynski N, Navarro T, Hobson N, Jeffery R, Keepanasseril $\mathrm{A}$, et al. Interventions for enhancing medication adherence. Cochrane Database Syst Rev. 2014;(11):CD000011.

8. Morgado MP, Morgado SR, Mendes LC, Pereira LJ, Castelo-Branco M. Pharmacist interventions to enhance blood pressure control and adherence to antihypertensive therapy: review and meta-analysis. Am J Health Syst Pharm. 2011;68(3):241-53.

9. Pringle JL, Boyer A, Conklin MH, McCullough JW, Aldridge A. The Pennsylvania project: pharmacist intervention improved medication adherence and reduced health care costs. Health Aff. 2014;33(8):1444-52.

10. Hiligsmann M, Salas M, Hughes DA, Manias E, Gwadry-Sridhar FH, Linck $\mathrm{P}$, et al. Interventions to improve osteoporosis medication adherence and persistence: a systematic review and literature appraisal by the ISPOR Medication Adherence \& Persistence Special Interest Group. Osteoporos Int. 2013;24(12):2907-18.

11. Cutrona SL, Choudhry NK, Fischer MA, Servi A, Liberman JN, Brennan $\mathrm{T}$, et al. Modes of delivery for interventions to improve cardiovascular medication adherence: review. Am J Manag Care. 2010;16(12):929-42.

12. Hojat M, Louis DZ, Markham FW, Wender R, Rabinowitz C, Gonnella JS. Physicians' empathy and clinical outcomes for diabetic patients. Acad Med. 2011;86(3):359-64.

13. Zolnierek KB, Dimatteo MR. Physician communication and patient adherence to treatment: a meta-analysis. Med Care. 2009;47(8):826-34.

14. Parchman ML, Zeber JE, Palmer RF. Participatory decision making, patient activation, medication adherence, and intermediate clinical outcomes in type 2 diabetes: a STARNet study. Ann Fam Med. 2010;8(5):410-7.
15. Bauer AM, Parker MM, Schillinger D, Katon W, Adler N, Adams AS, et al. Associations between antidepressant adherence and shared decision-making, patient-provider trust, and communication among adults with diabetes: diabetes study of Northern California (DISTANCE). J Gen Intern Med 2014;29(8):1139-47.

16. Rao JK, Anderson LA, Inui TS, Frankel RM. Communication interventions make a difference in conversations between physicians and patients: a systematic review of the evidence. Med Care. 2007;45(4):340-9.

17. Street RL Jr, Makoul G, Arora NK, Epstein RM. How does communication heal? Pathways linking clinician-patient communication to health outcomes. Patient Educ Couns. 2009;74(3):295-301.

18. Farzadnia $S$, Giles $H$. Patient-provider interaction: a communication accommodation theory perspective. Int J Soc Cult Lang. 2015;3(2):17-34

19. Jones L, Watson BM. Developments in health communication in the 21 st century. Lang Soc Psychol. 2012;31(4):415-36.

20. Hewett DG, Watson BM, Gallois C, Ward M, Leggett BA. Intergroup communication between hospital doctors: implications for quality of patien care. Soc Sci Med. 2009;69(12):1732-40.

21. Ryan EB, Maclean M, Orange J. Inappropriate accommodation in communication to elders: inferences about nonverbal correlates. Int J Aging Hum Dev. 1994;39(4):273-91.

22. Scholl I, Zill JM, Härter M, Dirmaier J. An integrative model of patientcenteredness - a systematic review and concept analysis. PLoS One. 2014;9(9):e107828.

23. Giles H. Accommodating translational research. I Appl Commun Res. 2008;36(2):121-7.

24. Jones L, Woodhouse D, Rowe J. Effective nurse parent communication: a study of parents' perceptions in the NICU environment. Patient Educ Couns 2007;69(1-3):206-12.

25. Watson BM, Gallois C. Communication accommodation between patients and health professionals: themes and strategies in satisfying and unsatisfying encounters. Int J Appl Linguist. 1999;9(2):167-80.

26. Coupland N, Coupland J, Giles H, Henwood K. Accommodating the elderly: invoking and extending a theory. Lang Soc. 1988;17(1):1-41.

27. Williams A. Communication accommodation theory and miscommunication: issues of awareness and communication dilemmas. Int J Appl Linguist. 1999;9(2):151-65

28. Jones E, Gallois C, Callan V, Barker M. Strategies of accommodation: development of a coding system for conversational interaction. J Lang Soc Psychol. 1999;18(2):123-51.

29. Lagacé M, Tanguay A, Lavallée ML, Laplante J, Robichaud S. The silent impact of ageist communication in long term care facilities: elders' perspectives on quality of life and coping strategies. J Aging Stud. 2012; 26(3):335-42

30. Gasiorek J, Giles H. Effects of inferred motive on evaluations of nonaccommodative communication. Hum Commun Res. 2012;38(3):309-31.

31. Chevalier BAM, Watson BM, Barras MA, Cottrell WN. Investigating strategies used by hospital pharmacists to effectively communicate with patients during medication counselling. Health Expect. 2017;20(5):1121-32.

32. Horne R, Weinman J, Hankins M. The beliefs about medicines questionnaire: the development and evaluation of a new method for assessing the cognitive representation of medication. Psychol Health. 1999;14(1):1-24.

33. Morisky DE, DiMatteo MR. Improving the measurement of self-reported medication nonadherence: response to authors. J Clin Epidemiol. 2011 64(3):255-63.

34. Morisky DE, Ang A, Krousel-Wood M, Ward HJ. Predictive validity of a medication adherence measure in an outpatient setting. J Clin Hypertens. 2008;10(5):348-54.

35. Tavakol M, Dennick R. Making sense of Cronbach's alpha. Int J Med Educ. 2011;2:53-5.

36. Pallant J. SPSS survival manual. 6th ed. Maidenhead (UK): McGraw-Hill House; 2013.

37. Krousel-Wood M, Islam T, Webber LS, Re R, Morisky DE, Muntner P. New medication adherence scale versus pharmacy fill rates in seniors with hypertension. Am J Manag Care. 2009;15(1):59-66.

38. Al-Qazaz HK, Hassali MA, Shafie AA, Sulaiman SA, Sundram S, Morisky DE. The eight-item Morisky Medication Adherence Scale MMAS translation and validation of the Malaysian version. Diabetes Res Clin Pract. 2010;90(2):216-21. 
This single copy is for your personal, non-commercial use only. For permission to reprint multiple copies or to order presentation-ready copies for distribution, contact CJHP at publications@cshp.pharmacy

39. de Oliveira-Filho AD, Morisky DE, Neves SJ, Costa FA, de Lyra DP Jr. The 8-item Morisky Medication Adherence Scale: validation of a BrazilianPortuguese version in hypertensive adults. Res Social Adm Pharm. 2014;10(3):554-61

40. Saeki H, Imafuku S, Abe M, Shintani Y, Onozuka D, Hagihara A, et al. Poor adherence to medication as assessed by the Morisky Medication Adherence Scale- 8 and low satisfaction with treatment in 237 psoriasis patients. J Dermatol. 2015;42(4):367-72.

41. Arnet I, Metaxas C, Walter PN, Morisky DE, Hersberger KE. The 8-item Morisky Medication Adherence Scale translated in German and validated against objective and subjective polypharmacy adherence measures in cardiovascular patients. J Eval Clin Pract. 2015;21(2):271-7.

42. Cohen J. Statistical power analysis for the behavioral sciences. 2nd ed. Lawrence Erlbaum Associates; 1988

43. White D. A service evaluation of acceptability and patient experience of pharmacy consultations conducted within a CBT framework. Eur J Hosp Pharm Sci Pract. 2014;21(3):170-4.

44. Bounthavong M, Christopher ML, Mendes MAS, Foster EB, Johns ST, Lim $\mathrm{L}$, et al. Measuring patient satisfaction in the Pharmacy Specialty Immunization Clinic: a pharmacist-run immunization clinic at the Veterans Affairs San Diego Healthcare System. Int J Pharm Pract. 2010;18(2):100-7.

45. Hale A, Coombes I, Stokes J, Aitken S, Clark F, Nissen L. Patient satisfaction from two studies of collaborative doctor-pharmacist prescribing in Australia. Health Expect. 2016;19(1):49-61.

46. Menckeberg TT, Bouvy ML, Bracke M, Kaptein AA, Leufkens HG, Raaijmakers JA, et al. Beliefs about medicines predict refill adherence to inhaled corticosteroids. J Psychosom Res. 2008;64(1):47-54.
Bernadette Chevalier, PhD, is an Honorary Fellow, School of Pharmacy, The University of Queensland, Queensland, Australia.

Bernadette M Watson, PhD, is a Professor in the Department of English and Director, International Research Centre for the Advancement of Health Communication, The Hong Kong Polytechnic University, Hong Kong, SAR.

Michael A Barras, PhD, is an Associate Professor in the School of Pharmacy, The University of Queensland, and Deputy-Director in the Pharmacy Department, Princess Alexandra Hospital, Queensland, Australia.

William N Cottrell, PhD, is an Associate Professor and Director, Interprofessional Education, Faculty of Health and Behavioural Sciences, The University of Queensland, Queensland, Australia.

Competing interests: None declared.

\section{Address correspondence to:}

Dr Bernadette Chevalier

School of Pharmacy, The University of Queensland

20 Cornwall Street

Woolloongabba, Brisbane QLD

Australia 4102

e-mail: b.chevalier@uq.edu.au

Funding: No external funding was received.

Acknowledgement: The authors gratefully acknowledge support provided by Metro North Hospital and Health Services in the conduct of this research. This study was conducted as part of Bernadette Chevalier's $\mathrm{PhD}$ research at The University of Queensland.
Canadian Society of Hospital Pharmacists

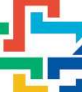

Société canadienne des

pharmaciens d'hôpitaux

\section{Good practice starts with membership.}

\section{Join more than 3,200 CSHP members and individual supporters dedicated} to leading and inspiring excellent hospital pharmacy practice.

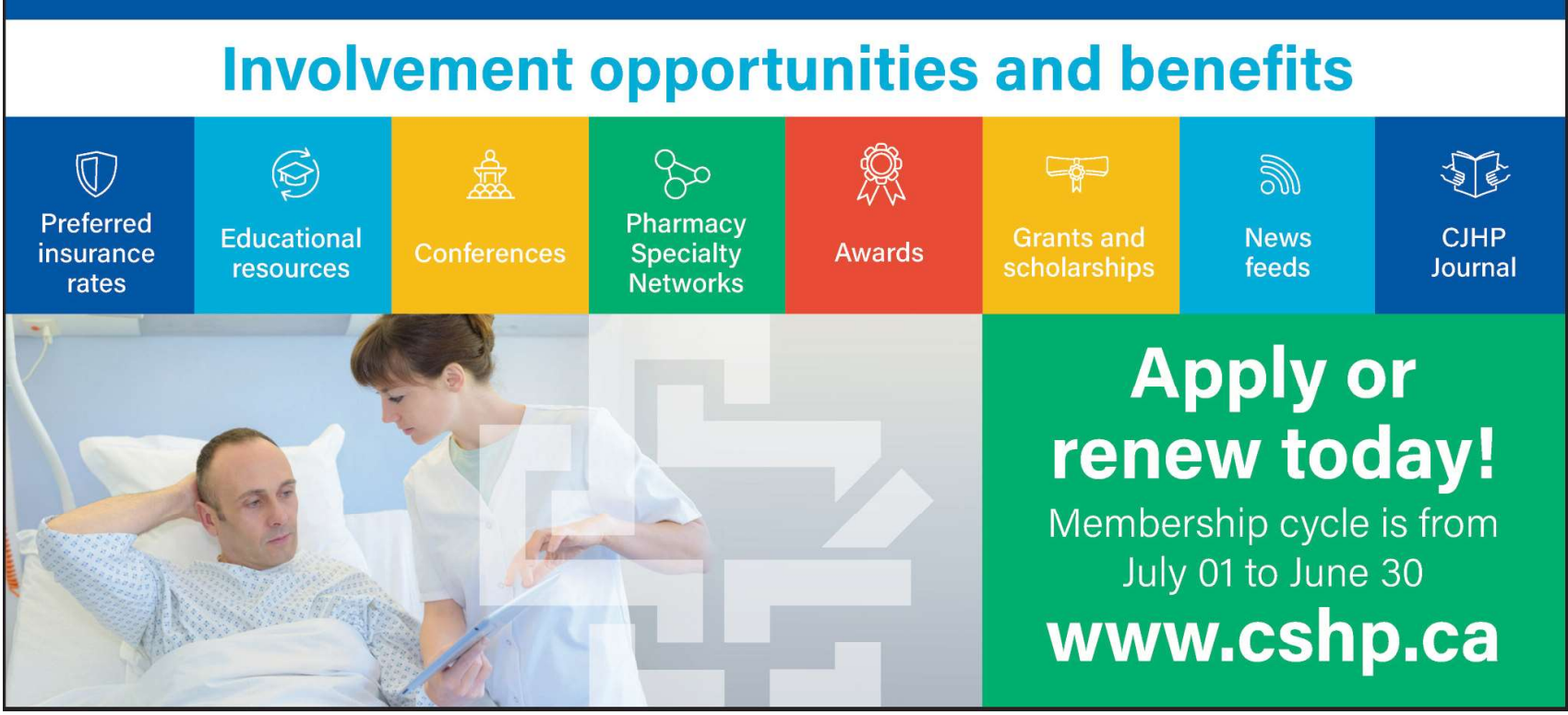

